\title{
Some Observations on the Problem of Sharing Experiences: Proust's À la recherche du temps perdu.
}

\author{
Juan S. Gómez-Jeria
}

\begin{abstract}
The problem of exchanging information about some unusual experiences is commented. The well-known internal experience of Proust and his madeleine is compared with an internal experience of the author. This comparison serves as a basis to suggest that some, but not all Homo sapiens sapiens may have some analogous but not equal internal experiences. The communication of internal experiences seems to be a very complicated problem in some disciplines. Other internal experiences are presented and discussed. The question of the biological value of some experiences is mentioned but no answer is provided.
\end{abstract}

Index Terms - Marcel Proust, LSD, internal experiences, mystical experience, altered states of consciousness, Great Language Barrier.

Language speaks and asks: "Why am I beautiful? Because my master bathes me". Paul Éluard, Capitale de la Douleur ${ }^{[1]}$.

\section{INTRODUCTION}

When I was young I had many internal experiences falling within the class of 'strongly altered states of consciousness'. At a certain moment I began to think (or to believe) that you can find a correlation, causal or not, between these states and brain functioning. With this idea in mind, a colleague and I wrote a couple of papers presenting the first neurobiological model of near-death experiences (NDEs). Later I wrote two papers commenting about reports of Mapuche and Chinese NDEs showing the influence of cultural factors on the content or subsequent report of the experience. At the end, and after publishing a paper showing that the list of 'uncommon' experiences was very long, that no one seemed to have provided scientific definitions for all them (exceptions might be the state or states experienced (or reached) just before falling asleep or just before awakening) and that our knowledge of brain functioning was very primitive, I stopped working on the problem [2]. Recently, and for different reasons, my interest returned. This text presents my thoughts about the internal experiences and their communication to other people. The hypothesis underlying this text is that I and all the possible readers have a common set of words having exactly the same meaning or meanings for all us ${ }^{[3]}$.

\section{ABOUT MYSTICAL EXPERIENCE(S)}

By chance I found a scientific paper (by scientific I understand only a text published in a scientific journal) about

Juan S. Gómez-Jeria, Faculty of Sciences, University/ of Chile. Santiago, Chile the 'mystical' experience. I searched for other scientific contributions and I was disappointed. The analysis of some of the results of that search seems to be a good starting point for the analysis of internal experiences.

In 1985 Fenwick et al. published a paper containing in its title the words 'mystical experience, [4]. I expected to find inside a kind of definition of 'mystical experience', but I found nothing. Instead of this I found a study of people claiming to have telepathy, clairvoyance, clairsentience, clairaudience, precognition, “intuition", dowsing, psychokinesis, mystical experience, mediumship, déjà vu, experience of past lives, inspirational speaking, poltergeist activity, and psychometry, encompassed as 'psychic gift(s)'. I could not understand why they are called 'gifts'. The first problem I found is that the authors stated that "no assumptions are made either about the effectiveness of the sensitivity, or the genuineness of the reported psychic gifts'. As the existence or not of these 'gifts' was not analyzed, in the worst case we are comparing two groups of subjects who are previously divided on the basis of a mental constitution leading the members of one group to state that they have 'gifts'. This looks like biting one's own tail. Now, considering that today there is a biological explanation of the déjà $v u$ experience, removing it from this list of 'gifts', and that a few hours of study will show the authors that the mystical experience has no relationship to the remaining members of their list, I think that this an excellent example of a potpourri fabricated without previous study and analysis of the phenomena intended to be studied. The conclusion of this paper ('there was evidence to suggest that some 'psychic' experiences were associated with brain dysfunction') rediscovers the well-known fact summarized in the expression 'blame the brain'. This is nothing new. We used this 'blaming' for the neurobiological modeling of near-death experiences. I thought of testing this paper by jumping from the roof of a second floor to try to become a telepath or to get a temporal lobe seizure to see if I acquire a ' $g$ ift' but instead I decided to continue writing this paper. The British Journal of Medical Psychology should be proud of this contribution. The next paper, authored by Beauregard and Paquette, intends to 'identify the neural correlates of a mystical experience' of Carmelite nuns by using magnetic resonance imaging ${ }^{[5]}$. The paper begins with a walk directly inside a conceptual marsh. The first phrase 'The turn of the new millennium has seen the emergence of "Spiritual neuroscience", a field of scientific investigation at the crossroads of psychology, religion and spirituality, and neuroscience' because it was not necessary to invent a new discipline to carry out this study. This reminds me of 
'disciplines' such as 'quantum psychology', 'quantum mysticism' and similar toroul boroul. I remind the authors that the 'new millennium' is only a time convention of a group of people and nothing else. Happily, and unlike the arrival of the year 1,000, no large crowds of hysterical people criscrossed the West shouting about the end of the world (with the exception of the 2012 Maya hysteria). Beauregard and Paquette stated that 'the brain activity of Carmelite nuns was measured while they were subjectively in a state of union with God'. From this phrase I realize that the mystical experience is understood as a 'state of union with God'. It is necessary to mention here, and this is of paramount importance, that the mystical and several other states 'lie' or 'are beyond' the Great Language Barrier (GLB). With LSD and in the course of the full hallucinogenic experience you may sometimes find certain states 'lying' beyond this GLB. The problem is that when the experiencer comes back to his/her usual daily state he/she crosses the Barrier back and is faced with the unsolvable problem of using language to explain the experience(s) to people who have never had a similar one. The second problem of this study is that the authors never measured a 'mystical state'. The authors stated that 'in the mystical condition, subjects were asked to remember and relive (eyes closed) the most intense mystical experience ever felt in their lives as a member of the Carmelite Order'. 'This strategy was adopted given that the nuns told us before the onset of the study that "God can't be summoned at will"'. This is nothing new (see for example Hippolytus of Rome, Refutation, Book V, 2.3.2 and 2.15). In this regard, I cite the first stanzas of John of the Cross' Dark Night of the Soul, where he mentions the first necessary but not sufficient condition (estando ya mi casa sosegada) to open the door to the experience of a high state of consciousness (I use Spanish because this text is really beautiful in its original language. English readers can find it on many sites in the Web).

En una noche oscura / con ansias en amores inflamada / ¡oh dichosa ventura! / sali sin ser notada, / estando ya mi casa sosegada.

A oscuras y segura, / por la secreta escala, disfrazada, / ¡oh dichosa ventura! / a oscuras y en celada, / estando ya mi casa sosegada.

The remainder of the paper is the attempt to correlate the functioning of brain structures with some reported pieces of the experience. For example, 'the caudate activations found here during the mystical condition were related with the feelings of joy and unconditional love'. I am excited at the possibility of buying a 'brain activation kit' (maybe at www.amazon.com). Obviously, the statement 'in our view, this does not represent a major problem since the phenomenological data indicate that the subjects actually experienced genuine mystical experiences during the mystical condition' is not true. During year 2016, Cristofori, Bulbulia, Shaver, Wilson, Krueger and Grafman published a paper about the neural correlates of mystical experience ${ }^{[6]}$. The authors begin by saying that 'mystical experiences can be defined as fusion with a supernatural agent', a quite unscientific statement. Notoriously, this definition is useless because science, by definition, does not deal with 'supernatural agents' (the definition is not theirs). In the Abstract of their paper they say that 'mystical experiences, or subjectively believed encounters with a supernatural world, are widely reported across cultures and throughout human history'. The expression 'subjectively believed' serves only for a deeper study of the expression 'supernatural world' (see my speculations about shamans ${ }^{[7]}$ ). The authors' investigation of the mystical experience among participants in the Vietnam Head Injury Study falls within the 'blame the brain' category. In the same year Liechti, Dolder and Schmid published a paper about 'alterations of consciousness and mystical-type experiences after acute LSD in humans' [8]. This paper is very interesting because the authors employ a cautious and elegant approach, despite the fact that they do not provide a definition of mystical or mystical-type experience(s). These authors find that mystical-type experiences were infrequent after LSD, possibly because of the set and setting used in their study. This is correct because people experiencing the mystical state know that you cannot get one when you want or seek it, 'at will' as said above by the nuns. Liechti et al. cite Alan Watts' definition of mystical experiences: '[Mystical experiences are] those peculiar states of consciousness in which the individual discovers himself to be one continuous process with God, with the Universe, with the Ground of Being, or whatever name he may use by cultural conditioning or personal preference for the ultimate and eternal reality'. Technically, if seems that Watts is talking about states beyond the GLB, whose explanation needs the use of language with the associated deformations due to cultural conditioning (God, Ground of Being, Universe, etc.). Unhappily, these states are neither mystical nor the ones described in general as 'burning' [9].

A suggested Gedankenexperiment: Take a nun or someone who is legally allowed to take LSD. Do a time-dependent (this is very important) MRI study. Ask the subject to 'return to normality' immediately after going through a mystical state (an almost impossible task) and analyze your MRI results of this time lapse. Repeat the study many, many times and maybe you will get something interesting and more or less exact to report. But first try to reach the 'mystical state' to know what you are looking for.

For the readers, here goes a description of a strong and full LSD experience (250 micrograms, summer, on the beach, no clouds): "This is the best way I can explain my experiences. My account is like trying to explain the sun using the flame of a lighter. I was on the beach, feeling each of the sun's rays arriving on my skin, feeling the wind passing, with a sensation of completeness and joy. At a later moment of the experience I was immersed in what I can describe as hallucinatory bursts accompanied by a dull murmur (I think it was the sea). Suddenly I was there, individually alone but at the same time fused with all things. I do not know how long this state lasted but suddenly I was ... I cannot explain it. I had this experience only once more in my life". The last state seems to be the mystical one. Unhappily, each time I wanted to write about this state, I wrote only stupid phrases. I think that there is no way to describe it, and this is the main and unsolvable problem the researcher will always face. For this specific experience I am certain that the interested researcher, 
before undertaking its study, must first have a mystical experience. I found more papers on this subject that are interesting but all fall under the same criticism.

It was interesting to discover that, despite the fact that I enjoyed the sand, the sea, the clouds, the rocks, etc. countless times during my childhood and when I was a young adult, new and marvelous phenomena can always be found when one is ready to perceive them. Here are three examples for the readers to think about: Stand on top of a cliff watching a small beach with the sand covered with pebbles. Each time the sea comes and goes, it moves many of them. Nevertheless, if you watch attentively you will notice that most of the pebbles point toward the same point in the sky. Now, you are on the beach watching the sunset. There are some clouds in the sky. You can see the sunlight on the clouds. If you watch attentively, you will notice that the shadows projected by the clouds on the sky are pale brown. Lastly, you are on a cliff watching the sea inside a bay. Twice a day the sea 'stops'. Reader, if you have never had these experiences and you find they are real, you will clearly understand the differences in human perception.

\section{EXPERIENCE AS A GENERATOR OF REAL AND NOT THEORETICAL} PHILOSOPHICAL PROBLEMS

Now I will comment on some personal experiences and what I have learned from them. I was really close to death on two occasions. In neither of them did I have NDEs. But the second time presented and still presents me with a real problem. Thinking back, I am sure that I should be dead by now. Until today I am still immersed in the problem of finding how to know whether I died and am now just dreaming that I am alive or I survived and am really alive. I have not been able to design an experiment allowing me to discern between these two possibilities. This problem is not new and is still unsolved, but there is nothing better to understand/feel its essence than having the real experience and not learning about it in a textbook or on a whiteboard.

Returning to NDEs, when thinking about these papers I noticed that, as I had no NDEs, I relied exclusively on what the experiencers reported. Moreover, I noticed a second, more subtle and more complex effect: the report of the experiencer is a function of the number and kinds of words that the experiencer knows at the time of the report. If one experiencer has the minimal number of words of his natural language allowing him to walk through life without problems before dying, and another experiencer is, for example, a good writer, their reports can be very different even if their experiences are exactly the same. Moreover, you must take into account the cultural environment of the experiencer and, more importantly, his mind structure: for people sharing the same historical origin and evolution it is easier to share, understand and interpret an internal experience than, for example, an Eskimo conversing with a Khoikhoi. These facts hold, not only for infrequent experiences such as NDEs, out-of-body experiences, etc., but also for the communication of everyday experiences. Ask a group of your students, on a yes/no basis, if they find that object X (a tree, a picture, etc.) is beautiful or not. After collecting the answers, ask them to clarify the reasons of their answers. At that moment you will probably find that what appeared to be a consensus about 'beautiful' or 'not beautiful' does not exist. And the problem of collecting and studying some experiences without experiencing them at least once seems to be one of the main unsolved problems of all human sciences.

Let us consider for example synesthesia: a neurological phenomenon in which stimulation of one sensory or cognitive pathway leads to automatic, involuntary experiences in a second sensory or cognitive pathway. But this is only a definition and says nothing about the experience itself. Surely, the supposed neural basis of synesthesia will be known sooner or later. I have had a number of experiences of this kind and, aside from the surprise and pleasure I felt, I have personal proof that this phenomenon called 'synesthesia' is real and not an invention. I am curious to know if all people studying synesthesia have experienced it. If you intend to properly study the internal experiences of others, you must experience all of them to be sure that they really exist and know with certainty that the names you give these experiences are the same given to these experiences by other people.

This is another complex experience. Suddenly the words of what was a normal conversation among friends were transformed into a succession of sounds with no meaning at all. At first I was afraid until I noticed that I was beginning to think with words again. This state lasted an indefinite time (minutes?). I cannot imagine what a reader that has not had such an experience will understand from this description. Neither can I imagine what the result will be of proposing a practical investigation of these experiences. This does not mean that science should refrain from studying these topics, but only shows what the real nature and magnitude of the problem that a scientist faces is when studying an experience he has never had.

\section{PROUST}

But there are a few cases in which the experiencer was so gifted that he was able to describe one of his experiences in such great detail that you can be (almost) sure that it was similar to one you had. Let us begin by telling my own experience. One day I was traveling in a taxi on a normal day and in my usual state of consciousness. A smell came into the taxi and suddenly a tsunami of memories flooded my consciousness. I remembered when I was a young boy eating a steak with rice prepared 'Chilean style' by my grandmother. I recalled the smell, the taste and the pleasure I felt each time I ate this 'delicacy'. I was so impressed that I later returned to the area where I had this delicious experience to see if there was an eating place around there, to see if the smell originated there and ask for a dinner with the secret hope of savoring this marvelous food again. I found nothing. But the experience was so strong that I decided to recreate the recipe to repeat the experience. In about one month I was able to recreate the dish with the same taste and smell I remembered. But the steak recipe was hard to crack. In a supermarket I bought, one by one, all the different cuts of beef and prepared them according to my memories of smell and taste with no results. Thinking of the problem I realized that many years ago the meat was bought at the local butcher's shop and not at big supermarkets 
(they did not exist). I went to one, I bought the correct beef cut, I prepared the rice, I prepared the meat and I ate the first mouthful. The experience was unbelievable. A second tsunami of memories emerged in my consciousness: the dining room, the windows, the color and taste of a drink, the tastes of previous meals and many other memories and feelings. I even saw my hands when eating! It was an almost ecstatic experience. Today, when I eat this dish again I still have a delicious experience but never the same as the first time.

And what about Proust? I read for the first time À la recherche du temps perdu in Spanish when I was about sixteen years old and found it boring. I read it again in French when I was enjoying Paris and again found it boring. But the third time I read it, it was after the abovementioned experience. I cite the famous and delicious portion about the madeleine (a small cake dipped in tea) ${ }^{[10-13]}$ : "She sent for one of those squat, plump little cakes called "petites madeleines," which look as though they had been moulded in the fluted valve of a scallop shell. And soon, mechanically, dispirited after a dreary day with the prospect of a depressing morrow, I raised to my lips a spoonful of the tea in which I had soaked a morsel of the cake. No sooner had the warm liquid mixed with the crumbs touched my palate than a shiver ran through me and I stopped, intent upon the extraordinary thing that was happening to me. An exquisite pleasure had invaded my senses, something isolated, detached, with no suggestion of its origin. And at once the vicissitudes of life had become indifferent to me, its disasters innocuous, its brevity illusory - this new sensation having had the effect, which love has, of filling me with a precious essence; or rather this essence was not in me, it was me. I had ceased now to feel mediocre, contingent, mortal. Whence could it have come to me, this all-powerful joy? I sensed that it was connected with the taste of the tea and the cake, but that it infinitely transcended those savours, could not, indeed, be of the same nature. Where did it come from? What did it mean? How could I seize and apprehend it? I drink a second mouthful, in which I find nothing more than in the first, then a third, which gives me rather less than the second. It is time to stop; the potion is losing its virtue'. Proust described his attempts to reproduce this moment but found, like me, that 'I retrace my thoughts to the moment at which I drank the first spoonful of tea. I rediscover the same state, illuminated by no fresh light'. This is the case of Proust and the madeleine. For further studies, Proust's notebooks can be found in the Bibliothèque numérique section of the Bibliothèque Nationale de France.

Happily, this time my reading of Proust's À la recherche du temps perdu was after the steak \& rice experience and I could connect to the above comments. What could both experiences tell me?

1. I can confidently hold the hypothesis that Proust and I had a similar experience and that in the case of Proust his experience was real and not a product of literary fantasy.

2. This experience has a biological basis that is related to the structure and functioning at least of what is called 'memory systems' in Homo sapiens sapiens ${ }^{[14]}$.

3. It is possible that some other members of the Homo sapiens sapiens subspecies could have a similar experience
[15]

It is clear that point 2 allows a scientific analysis of Proust's experience in terms of the biology of memory. I found many papers dealing with this relationship ${ }^{[16-22]}$. But, having had a similar experience (Hypothesis 1), I found that certain suggestions/comments/ideas in some of them deserve a comment. Troscianko states that “...Proust's engagement with contemporary science makes it likely that numerous currents of indirect influence and assimilation were at play in his fictional evocation of memory ..."[16] . I do not think so. I am sure that, if Troscianko one day has an experience like the one she is commenting on, she will rewrite several parts of her paper. Chu and Downes' paper states that "the Proust phenomenon is an enduring piece of folk wisdom that asserts that odors are particularly powerful autobiographical memory cues" "23] . I do not think so. Proust's text about the madeleine is not an enduring piece of folk but only a retelling of an experience by an experiencer. Moreover, Proust asserts nothing about odors: they appear in his story and nothing more. In another paper (a dispute with Jellinek ${ }^{[21]}$ ), Chu and Downes dare to declare that 'objectively, there is no reason to believe that the process of memory retrieval that Proust describes so eloquently, and in such tortuous detail, actually occurred, [24]. Perhaps the research on odor-evoked memories should be stopped and replaced by research on the 'incredible' ability of Proust to invent such a detailed account of an experience he never had. Conclusion after Proust and my steak \& rice: Chu, Downes and Jellinek never had a similar experience. Another good example of working with experiences never experienced. Also I did not undergo 'an overwhelming metaphysical vision' "25] or have an 'epiphany' [26]. The article of Shepherd-Barr and Shepherd is of enough interest to deserve to be read ${ }^{[27]}$. I found Kristeva's book of no interest ${ }^{[28]}$ (perhaps my steak $\&$ rice experience did not like it at all). Concerning what I said before about the mystic experience, Tukey's article about Proust contains some examples of the abuse and misuse of 'mystic' and 'mystical' [29]. Brodsky's article is a blatant example of how far from reality you can go! [30]. This article made me remember Feynman's words: 'psychoanalysis is not a science: it is at best a medical process, and perhaps even more like witch-doctoring' [my excuses to witch doctors!]. If you want to know more about what a simple madeleine can produce read the books of Carbone and Bales et al. $\stackrel{[31-33]}{ }$. With my modest steak \& rice experience I will never reach such heights of philosophical sophistication.

There is another experience Proust relates. Happily, this one can be easily reproduced by the reader only by finding the appropriate place with a stream with the right aquatic plant. 'At first they appeared singly - a lily, for instance, which the current, across whose path it was unhappily placed, would never leave at rest for a moment, so that, like a ferry-boat mechanically propelled, it would drift over to one bank only to return to the other, eternally repeating its double journey. Thrust towards the bank, its stalk would uncoil, lengthen, reach out, strain almost to breaking-point until the current again caught it, its green moorings swung back over their anchorage and brought the unhappy plant to what might fitly be called its starting-point, since it was fated not to rest there 
a moment before moving off once again. I would still find it there, on one walk after another, always in the same helpless state, suggesting certain victims of neurasthenia..'. This special lily may be associated with repeating cycles, the eternal return and whatever similar thing you have in your mind, but always a posteriori.

I had the following experience. I was on the beach with a good friend, meditating and walking close to the area reached by the waves. A group of small birds ran in what appeared to be a dance with the sea water: running slowly away when the water invaded the beach and running faster following the water when it retreated from (in fact, they were eating). I do not remember why I associated the birds' dance with the eternal return and life cycles but suddenly my friend told me something like this: 'yes, you are right: all things come and go'. After this we walked on without speaking. After this experience we never talked about what happened, I never felt in possession of a special 'gift' and we never created a New Church of Cycles! I relate this anecdote showing that reading about of one experience may elicit the memory of a totally different experience if both are linked by common elements (the cycles in this case).

\section{Speculations}

Be I will hold the hypothesis that I am a descendant of a Homo sapiens sapiens animal that crossed the before/after line I mentioned in another paper ${ }^{[3]}$. My problem now is how to know that my abovementioned experiences have been experienced by others. Based only on what I have read and talked about with many people I can accept that most of my experiences have been experienced by many, many people and that the problem is only the perfect sharing of them among people. This statement is probably fully true in the case of the basic Homo sapiens sapiens animal experiences such as anger, hunger, rage and other such. Experiences such as 'love', out-of-body, near-death, mystic, 'beauty' and many more do not seem to be within the reach of all, despite the fact that their names are used daily ('love' and 'beauty' specially). A fundamental question is if some of these experiences only appear in genetically gifted individuals or if some others are just disappearing.

The other important question is related to their biological value. The easy way is, as always, to dismiss most of them as a malfunctioning of the brain. But there is another possibility that needs to be explored. What if some of these experiences are experienced only by some candidates to replace our species in the future? These ideas will be explored later.

\section{REFERENCES}

[1] Laporte, D. History of Shit. MIT Press: Cambridge, Mass., 2000

[2] Gómez-Jeria, J. S.; Madrid-Aliste, C. Evolution and the Relationship Between Brain and Mind States. Journal of Near-Death Studies 1996, $14,251-272$.

[3] Gómez-Jeria, J. S. Biology and Philosophy. Part II. The Upper Paleolithic and the Holocene. World Journal of Research and Review 2017, 4, 42-47.

[4] Fenwick, P.; Galliano, S.; Coate, M. A.; Rippere, V.; Brown, D. 'Psychic sensitivity', mystical experience, head injury and brain pathology. British Journal of Medical Psychology 1985, 58, 35-44.

[5] Beauregard, M.; Paquette, V. Neural correlates of a mystical experience in Carmelite nuns. Neuroscience Letters 2006, 405, 186-190.
[6] Cristofori, I.; Bulbulia, J.; Shaver, J. H.; Wilson, M.; Krueger, F.; Grafman, J. Neural correlates of mystical experience. Neuropsychologia 2016, 80, 212-220.

[7] Gómez-Jeria, J. S. Biology and Philosophy. Part I. The Paleolithic. World Journal of Research and Review 2017, 4, 21-28.

[8] Liechti, M. E.; Dolder, P. C.; Schmid, Y. Alterations of consciousness and mystical-type experiences after acute LSD in humans. Psychopharmacology 2017, 234, 1499-1510.

[9] Magdeburg, M. o.; Tobin, F. J. The flowing light of the Godhead. Paulist Press: New York, 1998.

[10] Proust, M. In search of lost time: Vol. 1. Swann's way. The Modern Library: NY, 1992.

[11] Proust, M. À la recherche du temps perdu. [I], Du côté de chez Swann. Bernad Grasset: Paris, 1914

[12] Proust, M. A la recherche du temps perdu. I. Du coté de chez Swann. Gallimard: Paris, 1946

[13] Proust, M. En busca del tiempo perdido. I. Alianza Editorial: Madrid, 2015.

[14] Gluck, M. A.; Mercado, E.; Myers, C. E. Learning and memory: from brain to behavior. Third edition; Worth Publishers, Macmillan Learning: New York, 2016.

[15] Todd, R. M.; Palombo, D. J.; Levine, B.; Anderson, A. K. Genetic differences in emotionally enhanced memory. Neuropsychologia 2011 , 49, 734-744

[16] Troscianko, E. T. Cognitive realism and memory in Proust's madeleine episode. Memory Studies 2013, 6, 437-456.

[17] Toffolo, M. B. J.; Smeets, M. A. M.; van den Hout, M. A. Proust revisited: Odours as triggers of aversive memories. Cognition and Emotion 2012, 26, 83-92.

[18] Willander, J.; Larsson, M. Olfaction and emotion: The case of autobiographical memory. Memory \& Cognition 2007, 35, 1659-1663.

[19] Willander, J.; Larsson, M. Smell your way back to childhood Autobiographical odor memory. Psychonomic Bulletin \& Review 2006, $13,240-244$

[20] Bartsch, R. Memory and understanding: concept formation in Proust's A la recherche du temps perdu. John Benjamins: Amsterdam, 2005.

[21] Jellinek, J. S. Proust Remembered: Has Proust's Account of Odor-cued Autobiographical Memory Recall Really been Investigated? Chemical Senses 2004, 29, 455-458.

[22] Delacour, J. Proust's Contribution to the Psychology of Memory. Theory \& Psychology 2001, 11, 255-271.

[23] Chu, S.; Downes, J. J. Proust Reinterpreted: Can Proust's Account of Odour-cued Autobiographical Memory Recall Really be Investigated? A Reply to Jellinek. Chemical Senses 2004, 29, 459-461.

[24] Chu, S.; Downes, J. J. Proust nose best: Odors are better cues of autobiographical memory. Memory \& Cognition 2002, 30, 511-518.

[25] Bales, R. The Cambridge companion to Proust. Cambridge University Press: Cambridge, 2001.

[26] Goodkin, R. E. Around Proust. Princeton University Press: Princeton, N.J., 1991.

[27] Shepherd-Barr, K.; Shepherd, G. M. Madeleines and Neuromodernism: Reassessing Mechanisms of Autobiographical Memory in Proust. a/b: Auto/Biography Studies 1998, 13, 39-60.

[28] Kristeva, J. Proust and the sense of time. Faber and Faber: 1993.

[29] Tukey, A. Notes on Involuntary Memory in Proust. The French Review $1969,42,395-402$

[30] Brodsky, C. Remembering Swann: Memory and Representation in Proust. MLN 1987, 102, 1014-1042.

[31] Bales, R.; Harkness, N.; Schmid, M. Au seuil de la modernité: Proust, literature and the arts: essays in memory of Richard Bales. Peter Lang: Oxford; New York, 2011.

[32] Carbone, M. An unprecedented deformation: Marcel Proust and the sensible ideas. State University of New York Press: Albany, 2010; p.

[33] Bryden, M.; Topping, M. Beckett's Proust/Deleuze's Proust. Palgrave MacMillan: Basingstoke, Hampshire, UK, 2009. 
Some observations on the problem of sharing experiences: Proust's ì la recherche du temps perdu

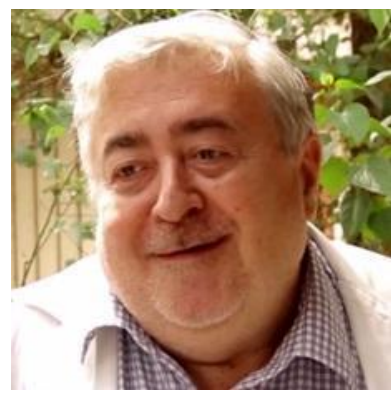

Dr. Juan Sebastián Gómez-Jeria. Graduate in Chemistry and Chemist at the University of Chile, PhD in Molecular Physical Chemistry (UNAB). Research in Quantitative Structure-Activity relationships, electronic structure of nanostructures and philosophy of science. Lecturer in Quantum Chemistry and Quantum Pharmacology, History and

Philosophy of Science. In charge of Physical Chemistry teaching Labs. He has published three books and more than 160 papers. 